\title{
Blog, wiki e mapas conceituais digitais no desenvolvimento de Projetos de Aprendizagem com alunos do Ensino Fundamental
}

\author{
Ítalo Modesto Dutra (Laboratório de Estudos em Educação a Distância - \\ italodutra@lead.cap.ufrgs.br) \\ Carlos Augusto Piccinini ( Laboratório de Estudos em Educação a Distância - \\ piccguto@yahoo.com.br) \\ Julia Lângaro Becker (Laboratório de Estudos em Educação a Distância - \\ julialbecker@gmail.com) \\ Stéfano Pupe Johann (Laboratório de Estudos em Educação a Distância - \\ stefanopj@gmail.com) \\ Léa da Cruz Fagundes (Laboratório de Estudos Cognitivos - leafagun@ufrgs.br)
}

Resumo: O Projeto Amora do Colégio de Aplicação da UFRGS, há 10 anos, vem construindo um modelo de trabalho que visa o desenvolvimento da autonomia e criatividade dos alunos. Os Projetos de Aprendizagem, em que a criança desenvolve pesquisas a respeito de temas científicos, aliam este objetivo ao uso de ferramentas de interação e intervenção suportadas por tecnologia. No presente artigo, é descrito o funcionamento do Projeto Amora e o uso de três ferramentas digitais: os blogs, os mapas conceituais (através do software CmapTools) e o wiki. Nos blogs, cada criança posta um diário com o aprendizado do projeto no dia. Os mapas conceituais são formas de representação alternativas a um texto escrito. O wiki é um sistema de construção de páginas na internet no qual as crianças desenvolvem as conclusões a respeito de seus projetos. Palavras-chave: Projetos de Aprendizagem, Ferramentas Digitais, Mapas Conceituais.

\begin{abstract}
The "Projeto Amora" of the "Colégio de Aplicação" of UFRGS, for 10 years, has been developing a work that aims the development of autonomy and creativity of the students. The Learning Projects, in which the child develops researchs about scientific subjects, couples this objective with the use of tools for interaction and intervention based on technology. In this article, the functioning of "Projeto Amora" and the use of three digital tools is described: blogs, concept maps (through the software CmapTools) and wiki. In blogs, every child posts a diary with what they learned in their projects every day. The concept maps are representations built in an alternative way to the written text. Wiki is a system of web site building in which children develop their conclusions about their projects. Keywords: Learning Projects, Digital Tools, Concept Maps.
\end{abstract}

\section{Introdução}

O Projeto Amora do Colégio de Aplicação da UFRGS (Lacerda et al 1999), em execução desde 1996, pretende desenvolver um modelo de mudanças na Escola que corresponda às necessidades geradas pelas transformações sociais (multiplicação de conhecimentos, acesso amplo às informações, trabalho colaborativo, autonomia e criatividade) e às múltiplas possibilidades que se tornam disponíveis pela aplicação das tecnologias digitais. Ele se constitui em um projeto de reestruturação curricular, caracterizada tanto pelos novos papéis do professor e do aluno quanto pela integração das TIC (tecnologia de informação e comunicação) ao currículo escolar. Ambos, professor e aluno, são desafiados constantemente na busca de solução para os problemas 
que encontram e na construção do conhecimento. O projeto envolve todos os alunos de 5a e 6a séries do Ensino Fundamental do Colégio de Aplicação da UFRGS (não há turmas de "controle").

Os projetos de aprendizagem, portanto, são usados com o objetivo de mudar a prática de ensino no que se refere às aplicações das tecnologias, invertendo essa lógica para uma prática que privilegie a aprendizagem. Visando a interdisciplinaridade e o trabalho colaborativo, a maior parte das atividades do Projeto Amora é realizada sem a tradicional divisão em turmas ou em séries. Desse modo, as inovações introduzidas no cotidiano escolar, resultantes da implementação das atividades do Projeto Amora, geram a necessidade do desenvolvimento de novas metodologias e de instrumentos de acompanhamento da aprendizagem dos alunos (Conlon, 2004), intencionalmente planejados para oferecer aos professores subsídios mais qualificados, que possam implicar intervenções mais eficazes nesse contexto.

\section{O Projeto Amora e a Orientação das Atividades}

O modelo de orientação dos estudantes foi desenvolvido pelos professores que fazem parte da instituição que abriga o Projeto Amora. O estudo foi sendo construído a partir do acompanhamento do desenvolvimento das atividades de pesquisa e produções derivadas dos projetos de investigação dos grupos de alunos do Projeto Amora (em geral de 7 até 10 alunos), no período compreendido entre a formação dos grupos até a apresentação final das conclusões das investigações (aproximadamente três meses).

No que diz respeito às práticas que constituem a metodologia empregada atualmente pelos professores do Projeto Amora, podemos caracterizar o trabalho desenvolvido durante a realização dos projetos de investigação pelas seguintes afirmações:

a) Cada aluno habilita-se a participação em um grupo por uma escolha de tema justificada com uma pergunta de investigação.

b) Os alunos com perguntas relativas a temas considerados semelhantes ficam reunidos no mesmo grupo.

c) Há alunos que têm mais experiência nesse domínio de ações e outros que, às vezes, no início do ano letivo em que estão na $5^{\mathrm{a}}$ série, não têm nenhuma experiência.

d) A decisão acerca de que temas ou perguntas são semelhantes é tomada pelo grupo de professores orientadores e discutida com o grupo de alunos.

e) Cada professor orientador escolhe o tema (ou temas) que irá orientar. Em geral, o grupo de orientadores tem como consenso a escolha de temas não necessariamente próximos a sua formação acadêmica.

f) O grupo (professor orientador e alunos) tem duas reuniões semanais com duração de duas horas e quinze minutos cada.

g) Em geral, na primeira reunião do grupo, o professor orientador discute as questões de cada aluno no sentido a avaliar se elas podem gerar uma investigação ou se têm respostas diretas, como, por exemplo, qual o carro mais veloz? Nessa negociação o grupo de alunos interfere dando sugestões aos colegas.

h) Os alunos são incentivados a fazer consultas à sites na internet, pesquisar em livros disponíveis na biblioteca da escola, a consultar professores especialistas no assunto (da escola e geralmente fora do grupo de professores orientadores). 
Alguns deles, ainda, trocam e-mails com especialistas ou interessados no assunto, a partir de endereços eletrônicos encontrados em sites da internet. Outros trazem parentes próximos que sejam especialistas no assunto pesquisado pelo grupo.

i) Se há disponibilidade, alunos e professor orientador visitam locais que podem ser de interesse do projeto, por exemplo, os alunos que fazem pesquisas sobre o sistema solar visitam o Planetário.

j) As informações coletadas são apresentadas ao grupo em mini-seminários (denominados de rodadas pelos participantes do Projeto Amora) que são momentos de interação entre alunos e professores, em que as crianças apresentam suas descobertas e ouvem perguntas e sugestões de todos do grupo sobre os resultados alcançados.

k) Durante todo esse processo os alunos (individualmente ou em grupo) constroem páginas da internet onde registram tanto suas perguntas quanto suas descobertas.

1) Há uma solicitação por parte do professor orientador de que os alunos, individualmente, reúnam os materiais que encontram, os textos que produzem etc, em uma pasta (física) denominada portfolio.

m) Está disponível para cada grupo um fórum de discussões virtual onde podem ser trocadas mensagens entre os participantes do grupo e também por qualquer outra pessoa que chegue até o site do Projeto Amora e se interesse em participar.

n) Ao final de um período mais ou menos determinado (três meses) os alunos apresentam a produção do projeto (resultados) para todos os participantes do Projeto Amora e convidados (pais, alunos de outras séries da escola ou de outras escolas).

Para a orientação dos projetos de investigação, a estratégia a cada encontro consiste em propor determinadas atividades com a finalidade de acompanhar e registrar a construção das respostas para as perguntas propostas pelos alunos. Essas atividades envolvem a realização de experiências/simulações, a pesquisa em sites na internet, as rodadas, a construção de mapas conceituais e orientações. As informações colecionadas pelas crianças, portanto, e as suas conclusões parciais(obtenção de novas informações, formulações de hipóteses) feitas através da pesquisa e da interação com os colegas e professores, foram registradas em seus blogs (diários digitais da internet, feitos pelos próprios alunos, e que permitem a inserção de comentários, o salvamento de imagens ou outros arquivos como anexos em cada diário e uma biblioteca de links).

Dessa forma, as pesquisas em livros ou em sites da internet, os registros no blog bem como os mapas conceituais construídos, seriam os subsídios para a construção das páginas no wiki. Esse procedimento difere daquele adotado para a construção de páginas da internet no Projeto Amora no sentido que singularizar esse espaço (as páginas) para efetivamente representar as conclusões dos alunos bem como pela possibilidade do próprio sistema wiki de guardar um histórico de modificações. Escolhemos o sistema wiki para fazer o registro do desenho de conclusões dos sujeitos de tal forma que, segundo eles próprios, as páginas ali registradas representassem um produto "final" mais elaborado e que refletissem uma síntese do seu trabalho.

Quanto à construção dos mapas conceituais, pretendíamos, inicialmente, que tais revisões ocorressem com freqüência semanal o que, logo na segunda semana de acompanhamento, ficou claro ser inviável. O tempo dedicado ao trabalho de busca e seleção de informações (entre uma semana e a seguinte) não pareceu que pudesse refletir em alguma necessidade dos alunos em alterar seus mapas. Foi preciso, também, levar em consideração a resistência das próprias crianças que por vezes expressavam 
sua avaliação da atividade classificando-a de "muito difícil" além de sua clara predileção pelo uso do blog como forma de registro. Assim, a freqüência de uma revisão do mapa conceitual a cada oito encontros (o que resulta em aproximadamente um mês entre cada uma) foi a adotada.

Quanto à orientação dos alunos, privilegia-se as ações dos professores no sentido de apontar possíveis contradições, contrapor e/ou oferecer novas informações, embora o ponto de referência seja caracterizado principalmente em auxiliar as crianças a chegar em alguma de forma autônoma. Destacamos, assim, estas modificações de algumas das rotinas usuais do trabalho com os projetos de investigação no Projeto Amora. Essas modificações refletiram nossa intenção de ter uma produção fiel e sistemática das reflexões dos alunos, o que viabiliza um melhor acompanhamento, além de potencializar o processo de aprendizagem:

a) os alunos construir, individualmente, mapas conceituais sobre seus assuntos de pesquisa que foram revisados (modificados) sistematicamente a cada quatro semanas (aproximadamente);

b) o portfolio foi substituído pelo blog digital; e

c) as páginas da internet deixaram de ser elaboradas usando um editor de páginas comum (Mozilla Composer, Microsoft Frontpage Express etc) e passaram a ser construídas em um wiki.

A novidade mais evidente, como não poderia deixar de ser, é o uso da construção de mapas conceituais. No caso do blog, se comparado ao portfolio, temos a vantagem de um espaço virtual que organiza automaticamente a cronologia das produções permitindo o acesso a qualquer momento tanto por parte do professor quanto por parte da criança. Por fim, o controle de versões possibilitado por um sistema wiki é um avanço extraordinário no que diz respeito ao acompanhamento do trabalho dos alunos.

\section{Dispositivos utilizados na orientação dos projetos}

A utilização de ambientes, de softwares ou de determinados sistemas de informática integra o modelo de acompanhamento que estamos construindo na medida em que tais dispositivos computacionais recolhem e organizam de diversas maneiras as representações construídas pelos sujeitos que os usam. Por essa razão, as funcionalidades desses dispositivos foram exploradas como parte integrante das estratégias de ação propostas para a orientação dos projetos. Conseqüentemente, as solicitações feitas às crianças, no desenrolar de suas ações interferiram de forma significativa no tipo e na qualidade dos registros que as mesmas produziram. 


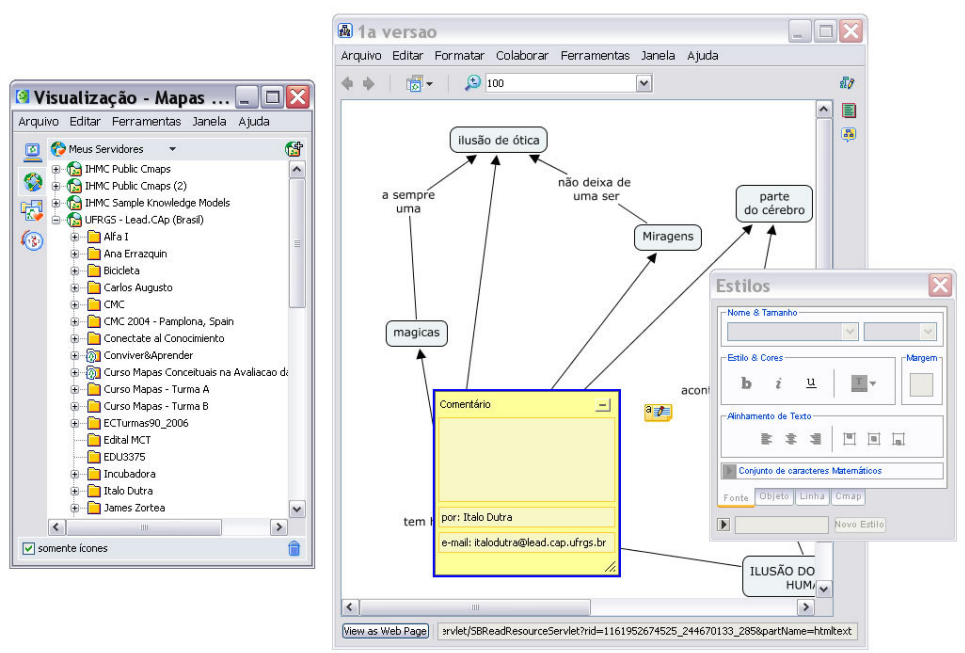

Figura 1: O software CmapTools

Todos os mapas conceituais produzidos pelos estudantes foram construídos usando o software CmapTools. Para isso, cada criança recebeu instruções básicas a respeito de como fazer para localizar e executar o programa. Além disso, cada uma delas tinha sua própria pasta disponibilizada em um servidor de mapas conceituais de tal forma que a cada sessão de trabalho que implicava a construção de um mapa conceitual essa versão era salva na pasta de cada aluno.

Como orientação inicial para o trabalho com os mapas conceituais a cada sujeito foi solicitada uma lista de palavras-chave (no mínimo cinco e no máximo de dez palavras para essa primeira lista) que, segundo a perspectiva de cada um deles, seriam importantes para explicar o seu tema ou, ainda, deveriam ser pesquisadas para ajudar na construção da resposta de sua pergunta inicial. De posse desta lista de palavras as crianças receberam a orientação sobre como proceder para construir um mapa conceitual. Essa orientação estava baseada em duas regras básicas. A primeira era a de que sempre deveria haver um verbo - conjugado corretamente - na ligação entre as duas palavras-chave (conceitos). A segunda era que todo conjunto CONCEITO $1 \rightarrow$ FRASE $\mathrm{DE}$ LIGAÇÃO $\rightarrow$ CONCEITO 2 formasse uma sentença completa e que fizesse sentido sozinha.

Para a produção de cada uma das versões seguintes do mapa conceitual adotamos procedimentos distintos. Para a segunda versão do mapa conceitual a única orientação foi a de que eles retomassem seus primeiros mapas e os completassem se julgassem necessário fazê-lo com novos conceitos ou novas ligações ou, ainda, que os corrigissem se houvesse a necessidade de modificar alguns dos conceitos ou ligações ali presentes. Essa tarefa foi realizada sem nenhuma intervenção direta por parte do pesquisador ou dos auxiliares nos mapas dos sujeitos. Colocamos, para ilustração, uma sequência de dois mapas conceituais(terceira e quarta versão) produzidos por um dos alunos do Projeto Amora. 

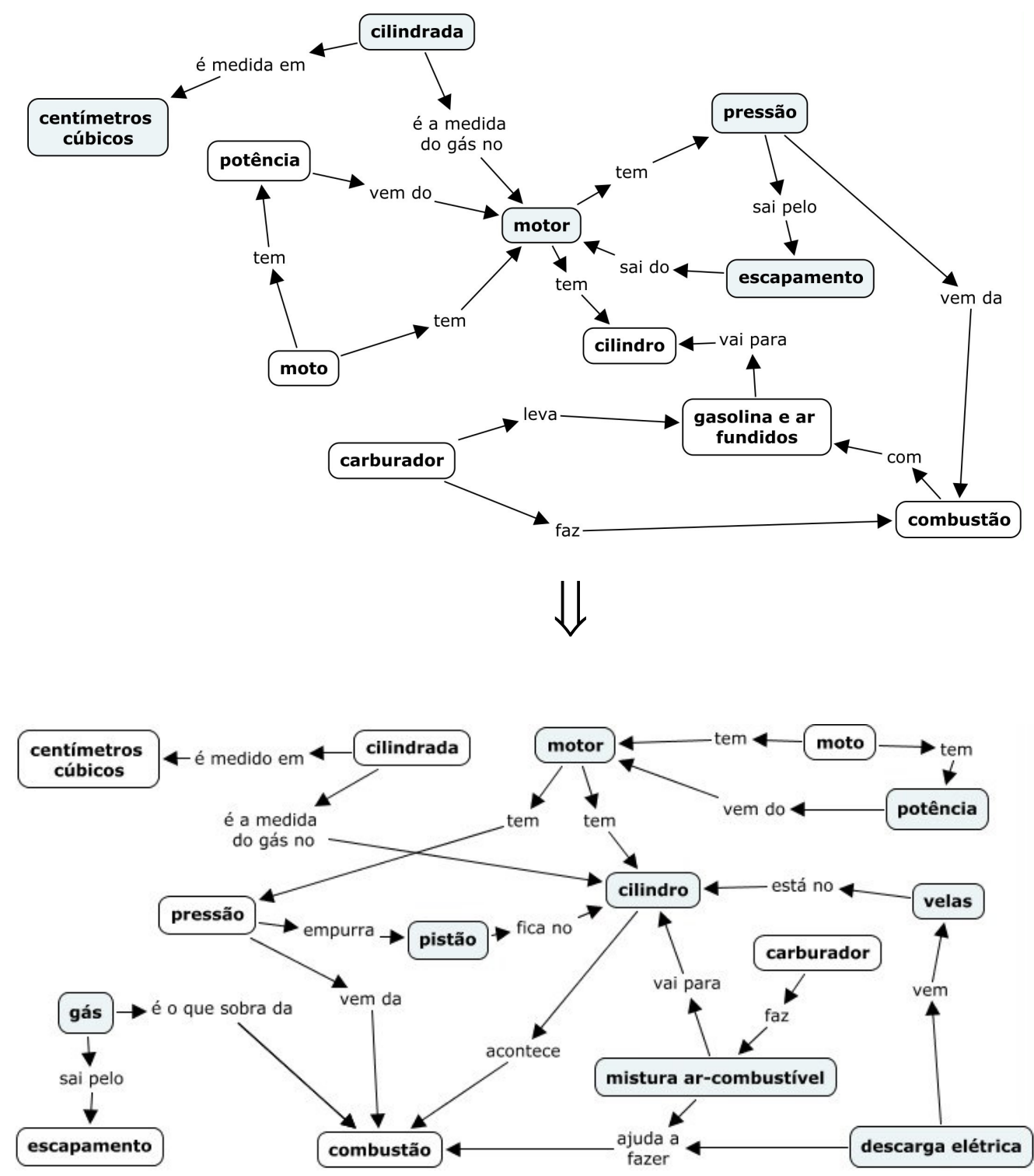

Figura 2: Seqüência de mapas conceituais produzidos por um mesmo sujeito

Na elaboração da terceira versão, foi feita a mesma solicitação anterior com a combinação de que, quando cada criança se desse por satisfeita e decidisse que não havia mais nenhuma modificação a ser feita, elas são entrevistadas pelo professor orientdor. A quarta versão foi construída na mesma sessão de trabalho em que foi feita a terceira. Essa quarta versão resultou da entrevista feita usando-se unicamente a terceira versão do mapa conceitual. Durante a entrevista, a cada explicação nova ou tomada de consciência do sujeito a respeito das relações ali explicitadas o professor solicitava à criança que incorporasse, da maneira que achasse melhor, aquilo que tinha dito em seu mapa conceitual. Por fim, a última versão do mapa conceitual foi construída após uma rodada de comentários realizados diretamente no mapa conceitual de cada sujeito usando uma funcionalidade (os Comentários) do CmapTools. Esses comentários foram feitos pelas próprias crianças nos mapas uns dos outros. 
O Blog utilizado para a orientação dos projetos é denominado AçaíBlog. Elaborado pelo próprio Le@d.CAp, possui diversas ferramentas que auxiliam os alunos em seus projetos. A construção, bem como a utilização deste blog ocorre principalmente pela possibilidade de registro das atividades realizadas pelos estudantes, bem como o potencial de interação, pois é possível a qualquer pessoa ter acesso a estes diários e comentá-los. Estas características entram em convergência com a orientação dada aos alunos, onde o registro das atividades ocorre na produção de Diários, no qual é proposto às crianças que escrevam, com suas próprias palavras, o que compreenderam das suas investigações daquele dia. Destacando a necessidade de que estas crianças sejam autoras do próprio conhecimento.

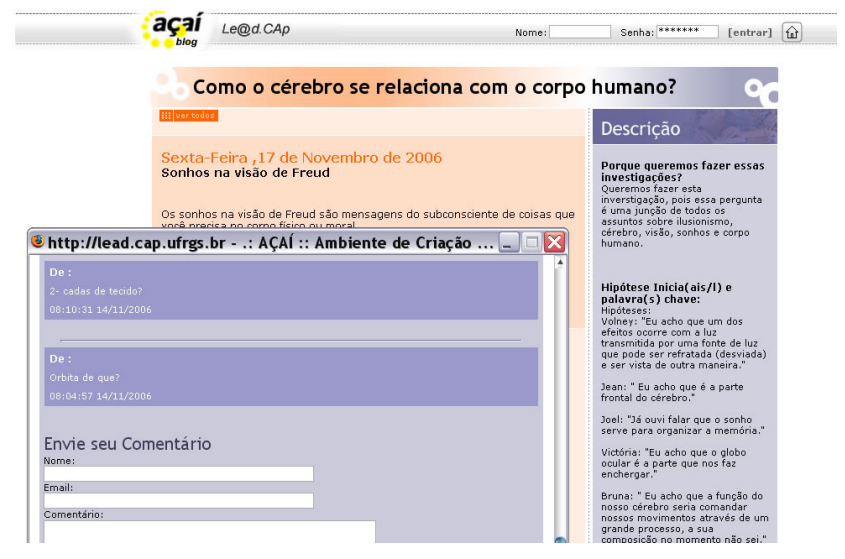

Figura 3: O Açaí Blog

Como se vê normalmente o aparecimento de diários, no qual denominamos de "trilha", em que a criança descreve o que fez ("às oito horas fui a biblioteca..."), orientase, sempre que este conteúdo explicite o que foi aprendido. Quando as crianças vão realizar a sua pesquisa na biblioteca, orientamos para a leitura sobre algum ponto do projeto e a produção de um texto com o que foi pesquisado, sempre com as próprias palavras da criança, com o próprio entendimento. Há ainda um espaço que possibilita o envio de imagens referentes ao projeto. Logo abaixo um exemplo de diário de uma aluna. Uma das orientações realizadas, foi o estímulo para que cada aluno comente os diários dos seus colegas. Logo abaixo, portanto, estão os comentários do referido diário.

a) Diário:

Orgãos.

Na biblioteca eu encontrei informações como:

1-Cada uma das partes, de um organismo que se incube de realizar certa função espacifica.

2-O coração e os vasos sanguinios e o sangue forma o sistema cardiovascular.

3-O cerebro, os nervos e os tecidos ligados a eles forman o sistema nervoso.

4-A boca o estomago e os intestinos trabalham juntos como membros do sistems digestório.

5-Os músculos respiratórios as veias 
respiratória(NARIZ,BOCA,FARINGE,LARINGE E TRANQUEIA) os pulmões trabalham juntos fomando o sistema respiratório.

6- Do que é feito o corpo humano?

-células vivas.

-o laberinto intracélulas.

*TODOS OS SISTEMAS JUNTOS FORMAM O SEU ORGANISMO.

Postado por: DIE em 14.11.2006 às 07:16 [4]comentário(s)

b)Comentários:

De : BRU

Acharia melhor se você revisase o seu texto por que há alguns erros de ortografia, achei muito legal a estrutura do teu texto.

08:46:22 14/11/2006

De : VIC

Dienifer eu achei bem interesante a tua pesquisa, mas tem palavras que eu não conheço, tipo labirinto intracélulas e essas coisas, mas mesmo assim eu ache muito interesante o tue projeto

08:41:47 14/11/2006

De : VOL

Eu acho que você poderia explicar o que é um LABIRINTO intracélulas.

08:15:11 14/11/2006

De : JEA

O que é o organismo e quantas partes são?

08:12:50 14/11/2006

Desde 1996, uma das maiores novidades que o Projeto Amora apresenta são as páginas para a internet construídas por seus alunos. Elas abrigam todo o desenvolvimento das atividades de pesquisa dos diferentes grupos de alunos o que implica em uma organização própria por parte deles na sequiência como são apresentadas as informações bem como das possibilidades de se estabelecer relações entre as informações sob a forma de hipertexto.

Os aspectos técnicos envolvidos na confecção de páginas para a internet (usando-se editores de páginas tais como o Mozilla Composer ou o Microsoft Frontpage Express) e a sua publicação em um servidor trazem consigo uma série de dificuldades que, por vezes, tomam bastante tempo das atividades de desenvolvimento dos projetos de aprendizagem: a perda de dados (que em geral são armazenados em disquetes que facilmente são perdidos ou deixam de funcionar), o mau uso da sintaxe da linguagem HTML (não exibição de figuras adicionadas ao texto, links "quebrados") ou, ainda, a necessidade de se usar um programa específico para publicação das páginas (envio a um servidor da internet).

Vários desses obstáculos são, de longe, superados com o uso de um sistema wiki para o armazenamento de páginas da internet. Esse sistema permite a edição online das páginas sem a eventual necessidade de qualquer transporte físico de informações (tais 
como os disquetes). Além disso, em um wiki é possível armazenar todas as transformações ocorridas em uma página sendo possível comparar o histórico de tais modificações contendo dados, inclusive, do usuário do sistema responsável por cada edição. Esse tipo de sistema se popularizou com o surgimento da Wikipedia, uma enciclopédia virtual que reúne milhares de usuários na produção de artigos em dez línguas diferentes.

Para a realização do nosso estudo, utilizamos o mesmo sistema da Wikipedia instalado em um servidor no Colégio de Aplicação. Esse é um software livre disponibilizado para a instalação e desenvolvimento em http://mediawiki.org.

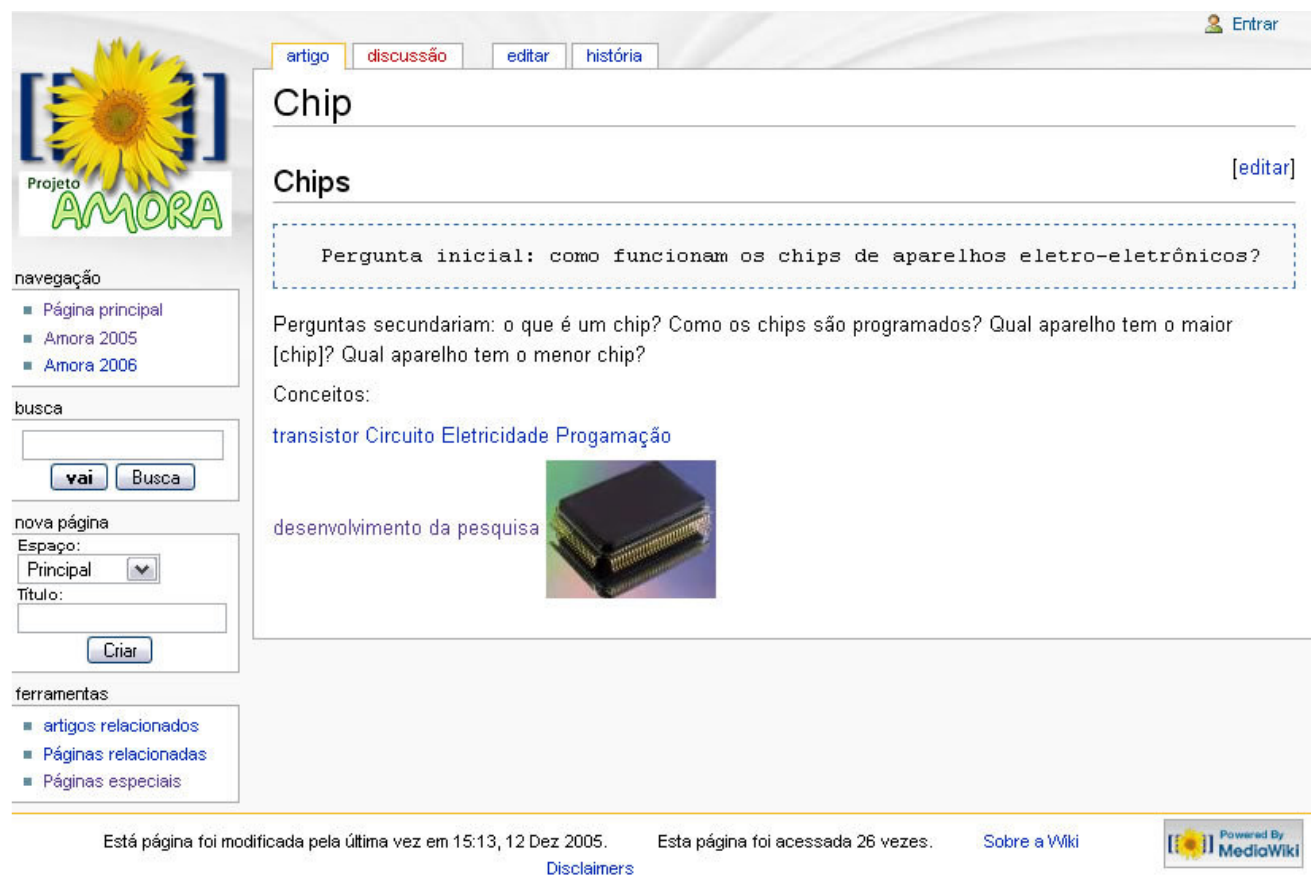

Figura 4: Tela do sistema MediaWiki usado no Projeto Amora

Diferentemente da utilização usual das páginas para a internet no Projeto Amora, optamos por usar o wiki em uma fase do desenvolvimento dos projetos em que já era possível, do ponto de vista das crianças envolvidas, escrever as conclusões das investigações. Até então, antes de acessarem o wiki, os sujeitos produziram ao menos duas versões de seus mapas conceituais e, também, colecionaram textos próprios, imagens e outros recursos em seus diários no AÇAÍ. Dessa forma, podemos coletar o que as crianças julgam ser as produções finais a respeito de suas investigações.

\section{Conclusões}

O Projeto Amora caracteriza-se por ser uma proposta que visa desenvolver a capacidade de autonomia dos alunos promovendo atividades que privilegiam diferentes formas de interação. Além disso, as atividades são planejadas para criar espaços para que o desenvolvimento e as aprendizagens das crianças possam ser acompanhados, possibilitando uma prática privilegia as intervenções capazes de auxiliá-las. 
Descrevemos as estratégias de uso de três dispositivos, que tanto auxiliam no registro das atividades, como também oferecem ferramentas que potencializam a interação, tanto dos alunos, como dos professores. É ainda necessário maiores investigações no sentido de elaborar intervenções que ofereçam um melhor aproveitamento destas ferramentas.

\section{Referências}

Cañas, A. J., Ford, K.M., Coffey, J., Reichherzer, T., Suri, N., Carff, R., Shamma, D., Hill, G., Hollinger, M. \& Mitrovich, T. (1999). Herramientas para Construir y Compartir Modelos de Conocimiento. In: 99 Workshop Internacional sobre Educação Virtual, Fortaleza, Brasil.

Cañas, A. J., Hill, G., Carff, R., Suri, N., Lott, J., Eskridge, T., Arroyo, M., Carvajal, R (2004). Cmaptools: a knowledge modeling and sharing environment. Concept Maps: Theory, Methodology, Technology 2004. First International Conference on Concept Mapping, Pamplona, Espanha.

Lacerda, R. P., Dutra, Í. M., Valentini, N. C., Camargo, F. B. \& Merg, Y. G. (1999). Projeto Amora 2000. Disponível em 04/2006 em http://amora.cap.ufrgs.br/2000/documentos/ProjetoAmora2000.doc.

Safayeni, F., Derbentseva, N. \& Cañas, A. J. (2003). Concept Maps: A Theoretical Note on the Need for Cyclic Concept Maps. Manuscrito não-publicado.

Cunha, M.J.S., Fernandes, E., Omar, C. T. \& Silva, N. V. (2004). Avaliação de Aprendizagem Significativa Usando Mapas Conceituais num Ambiente Cooperativo. Diversidade e Integração: Desafios para a Telemática na Educação, XV Simpósio Brasileiro de Informática na Educação, Manaus, Brasil.

Conlon, T. (2004). 'But is our concept map any good?': Classroom Experiences with the reasonable fallible analyser. Concept Maps: Theory, Methodology, Technology 2004. First International Conference on Concept Mapping, Pamplona, Espanha. 